\title{
DIABETIC FOOT ULCER; \\ RISK FACTORS STRATIFICATION IN PATIENTS. A STUDY OF 150 PATIENTS.
}

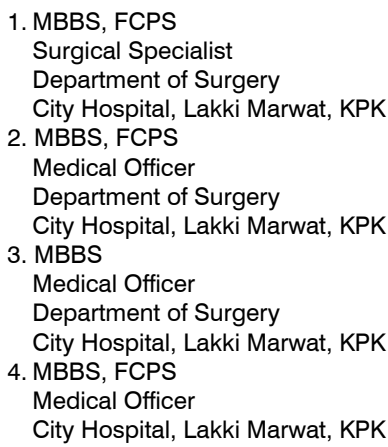

Correspondence Address:

Dr. Ishtiaq Ahmad

Medical Officer

City Hospital, Lakki Marwat

Khber Pukhtunkhwa

dr.ishtiaq@ymail.com

\section{Article received on:}

$11 / 02 / 2016$

Accepted for publication:

09/04/2016

Received after proof reading: 26/05/2016

\section{INTRODUCTION}

Diabetes mellitus is a syndrome with disordered metabolism and inappropriate hyperglycemia due to either a deficiency of insulin secretion or to a combination of insulin resistance and inadequate insulin secretion to compensate for the resistance. ${ }^{1}$ In 2014 the global prevalence of diabetes was estimated to be $9 \%$ among adults above age 18 years of age. In 2012 diabetes was the direct cause of 1.5 million deaths. More than $80 \%$ of deaths occur in low and middle income countries. ${ }^{2}$ WHO projects that diabetes will be the $7^{\text {th }}$ leading cause of death in $2030 .{ }^{3}$ Diabetes puts a lot of burden on the economy of countries where prevalence of diabetes is high. In 2007, 14 billion dollars were spent on the treatment of diabetic patients where diabetic foot ulcers (DFUs) contributed one third of the total cost. ${ }^{4,5}$ Pakistan is situated in high prevalence area $(5-7 \%)$ where 6.9 million people are affected by diabetes with the International Diabetes Federation estimation that this number will grow to 11.5 million by

\begin{abstract}
Dr. Abdul Waheed Jan', Dr. Hanifullah Khan², Dr. Ishtiaq Ahmad ${ }^{3}$, Dr. Matiullah Khan ${ }^{4}$
STACT... Objectives: To determine the risk factors contributing to the development of Patients and Material: One hundred and fifty diabetic patients with foot ulcer were studied. studied. The average diabetic duration was 11 years. HbA1c was more than $8 \%$ in $98(65.3 \%)$ patients. Peripheral neuropathy was present in 60 patients (40\%), peripheral vascular disease in 80 patients $(53.3 \%)$, neuro-ischemic ulcers in 45 patients $(30 \%)$, hypertension in 70 patients $(46.6 \%)$, Ischemic heart disease in $20 \%$, Dyslipidemia in $50 \%$, foot deformity in $42 \%$ and pecidental/ foot wear trauma in $44 \%$. Conclusion: Foot ulcer in diabetes results from multiple pathophysiologic mechanisms. Implementation of strategies for prevention, early detection, and appropriate treatment at the primary health care level are urgently needed.
\end{abstract}

Key words: Diabetes mellitus, Diabetic foot ulcers, Ischemia, Neuropathy, Dyslipidemia, Foot deformity. in patients. A study of 150 patients. Professional Med J 2016;23(6):693-698. DOI: $10.17957 / T P M J / 16.3288$

2025 unless measures are taken to control the disease. ${ }^{6,7}$

Currently, Pakistan is ranked $7^{\text {th }}$ in the list of countries with major burden of diabetes mellitus where as it is the $4^{\text {th }}$ leading cause of death in developed countries..$^{8,9}$

This grave situation is an alarming sign and a challenge for the health authorities in our country as well as abroad.

Diabetic foot ulcers are one of the most common complications of diabetes mellitus. About 20-40\% of diabetic patients suffer diabetic neuropathy of which almost $50 \%$ usually develop symptomatic peripheral vascular disease within twenty years of diagnosis. The lifetime prevalence of foot ulceration is about $15 \%$ and diabetes is an important non-traumatic cause of major amputations of the lower limbs. ${ }^{10,11}$

Lower-limb amputation and foot ulcer results in 
considerable morbidity, mortality, and health care expenditures among patients with diabetes. More than half of lower-limb amputations in the U.S. occur in patients with diagnosed diabetes, who comprise only $3 \%$ of the U.S. population. ${ }^{12}$ A study conducted by Reiber GE et al, United States in 1995, nonhealing foot ulcer preceded $85 \%$ of diabetic lower-limb amputations. ${ }^{13}$

Foot ulcers are usually divided into two groups. Acute ulcers occur due to poorly fitting shoes and other minor trauma. Chronic planter ulcers occur over weight bearing areas. In most cases, the initiating event is a minor trauma. The recognized causal pathways leading to diabetic foot ulcers and then amputations alone or in combinations are neuropathy, ischemia, infections, impaired wound healing, minor trauma, dermal abrasions and gangrene. ${ }^{13,14,16}$ Poor glycemic control is a recognized risk factor. ${ }^{17}$ The frequent evaluation of the feet in diabetic patients is important to identify those at risk for foot ulceration. ${ }^{16,18}$ The cost implication of hospital care, treatment products, nursing, dressing and debridement, amputations, rehabilitation and long term care, social support, transport and provision of orthoses is very high. Besides this, heavy psychological burden due to morbid life have a significant impact on healing. ${ }^{19}$ Hence the lone solution is early identification with proper treatment of diabetic foot ulcers which will go a long way in improving clinical and economic outcome. This calls for prevention of diabetes, its complications, prevention of foot ulcers and prevention of amputations.

The aim of the present study is to find out the risk factors contributing to the development of diabetic foot ulcers so that early measures be taken to prevent their occurrence.

\section{PATIENTS AND METHODS}

This single center descriptive observational study was conducted in the Department of Surgery, City Hospital Lakki Marwat, Khyber Pukhtunkhwa

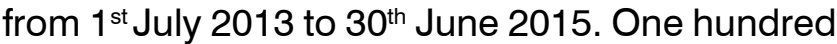
and fifty patients with diabetes mellitus and foot ulcer were studied. Ninety five were male and 55 were female. Informed consent was obtained from all patients. Patients who had bilateral foot amputation, wheel chair bound or unable to walk, foot ulcers due to vasculitis/ artertitis, too sick patients to participate in trial, diabetics without foot problems and all patients who refused to participate in the study were excluded from the study. All patients were interviewed to collect data on demographics, socio-economic conditions of the patients, smoking history, self-care behaviors and any delay in seeking proper treatment. Lower limbs of all patients were thoroughly examined along with general physical examination. Particular attention was given to evidence of hypertension, heart and renal failure, ischemic foot (cold skin, weak peripheral pulses), neuropathy (insensitive foot, loss of vibration and position sense), foot deformity (claw toes, call us at pressure areas and Charcot joints), visual acuity with Snellen Chart, immobility of patient (stroke, frailty), footwear trauma, accidental trauma (Thorne, glass, insect bite) infection in feet (bacterial and fungal) and neglected foot (unawareness on patient's side). Various investigations were performed including fasting and random blood sugar, lipid and renal profile, HbA1c level, chest X-ray, X-ray foot, echocardiography, urine examination, swabs culture from wounds. After the completion of 150 cases, all the proformas were analyzed for the results.

\section{RESULTS}

One hundred and fifty patients including 95 (63\%) male and 55 (37\%) female were studied as shown in Figure-1.

Most of the patients (65\%) were above 50 years of age while only 5 patients (3.3\%) were below 30 years of age. The mean age was 55 years.

The average diabetic duration was 11 years. 93\% patients had type 2 diabetes mellitus and only $7 \%$ had type 1 diabetes in only $7 \%$ of patients. Of the total 150 diabetic patients, 139 contributed both lower limbs while 11 amputee diabetic patients contributed only one limb. The mean body mass index (BMI) was more than 25.1 in male patients and 28.2 in female patients. Fifteen (10\%) patients were smokers. HbA1c 
was more than $8 \%$ in 98 (65.3\%) patients and less than $6 \%$ in none. Peripheral neuropathy was present in 60 patients (40\%), peripheral vascular disease in 80 patients (53.3\%), neuro-ischemic ulcers in 45 patients (30\%), hypertension in 70 patients $(46.6 \%)$, retinopathy in 18 patients (12\%). Ischemic heart disease and nephropathy was present in 30 patients (20\%) and 20 patients (13.3\%) respectively. Lipid profile was deranged in 75 patients (50\%). Structural foot deformity was present in 63 patients (42\%). Thirty five patients (23.3\%) were immobile either due to loss of vision or stroke or frailty. Trauma either accidental or foot wear were noted in 66 patients (44\%). Infected foot ulcers were noted in 112 patients $(74 \%)$. These results are shown in figure- 2 .

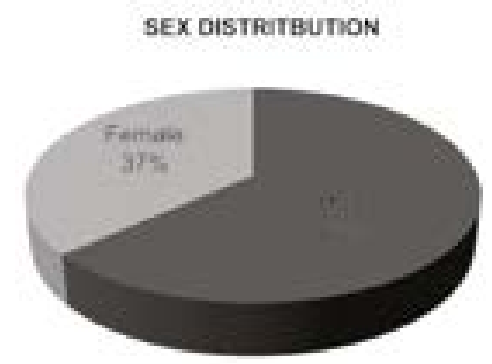

Figure-1.

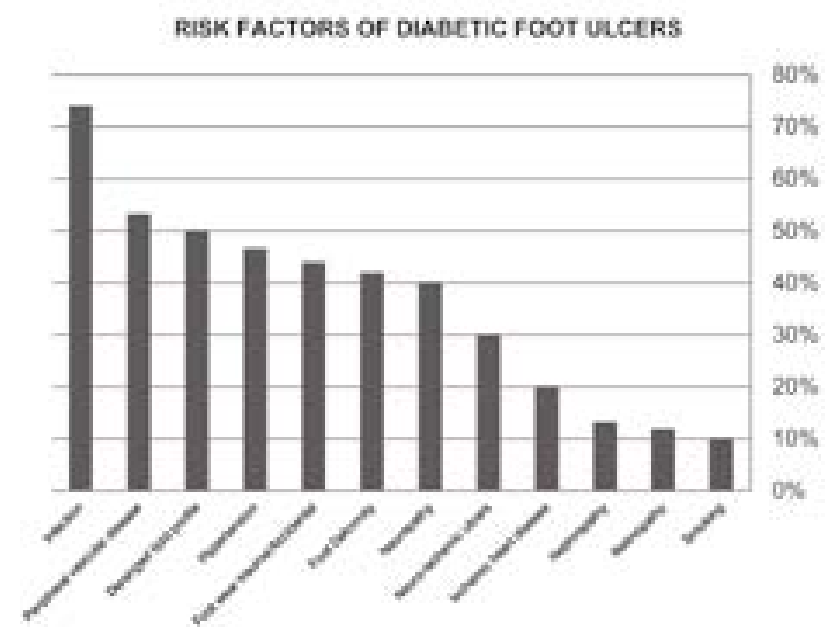

Figure-2

\section{DISCUSSION}

Diabetic foot is one of the many serious life threatening complications having major medical and socio-economic consequences. Nearly 15
$\%$ of all diabetics will develop foot ulcers during the course of their illness. ${ }^{20,21}$ Macro and microangiopathy and neuropathy play a major role in causation, progression and healing of diabetic foot ulcers. ${ }^{22}$ Foot infection and the subsequent amputation of a lower extremity are the most common cause of hospitalization among diabetic patients. ${ }^{23}$ There are multiple contributory factors and there is evidence to suggest that up to $50 \%$ of foot ulcers and amputations could be prevented by early identification of the risk factors, their management and education of the patients. ${ }^{24}$

We studied the contributory risk factors for foot ulcers in 150 diabetic patients with diabetic foot ulcers. Male to female ratio was almost 3:2. The male predominance was also evidenced in other local studies conducted by Muqim R, et al where male predominance was $62 \%$ and Khan $\mathrm{H}$, et al where male predominance was $63 \% .^{25,26} \mathrm{~A}$ study conducted in Bahrain, females outnumbered males in a ratio of 1.3:1 which contradicts our study. ${ }^{27}$ The more prevalence in males in our set up may be due to more exposure to trivial foot injury, foot wear trauma and bare foot walking.

Sixty five percent of the patients were above the age of 50 . In most of the studies conducted locally or abroad, the mean age of the patients was $>50$ years which coincides well with our study. ${ }^{26-28}$

The average duration of disease was more than 11 years in our study. A study conducted by Edward $\mathrm{J}$, et al the average duration of diabetes mellitus was 11.4 years which match our results. ${ }^{29}$ Same result is also evidenced in another study. ${ }^{30}$ Mean duration of 15 years was seen in a local study. ${ }^{31}$ The longer the duration of diabetes, the higher are the chances of diabetic foot ulcers. ${ }^{29,32}$

The mean BMI was 28.2 in female diabetic patient. Obesity is very common in our set up especially in female population. The main cause may be over eating habits, lack of exercise and poor health education. Obesity is mentioned as a risk factor in diabetic foot ulcers in other studies. ${ }^{26,27,33}$

Smoking is an independent risk factor for diabetic 
foot ulcer. ${ }^{26,29}$ Smoking leads to peripheral vascular disease, dyslipidemia, ischemic heart diseases and ischemic foot. Although less common in our society as compared to western societies, still it was present in $10 \%$ of our study population.

Neuropathy, peripheral vascular disease and neuro-ischemic ulcers were found in $40 \%$, $53.3 \%$ and $30 \%$ diabetic patients respectively. Peripheral neuropathy and peripheral vascular diseases are the major complications of diabetes mellitus leading to foot ulceration, infection and amputation. ${ }^{13,17,34}$ Prevalence rates of neuropathy and its complications are high in our society as compared to Western or American society which may be due to better management of diabetes, better foot care and better health education. A local study conducted by Khan $\mathrm{H}$, et al, neuropathy, ischemia and neuro-ischemic foot ulcers were present in $86 \% 72 \%$ and $43 \%$ diabetic patients which is higher than our study. ${ }^{26}$ Another study conducted in UAE showed peripheral neuropathy in $30 \%$ and PVD in $13 \%$ patients which is quite low as compared to our study. ${ }^{34}$ Ali SM, el al found neuropathic ulcers in $42 \%$ and neuro-ischemic in $58 \% .{ }^{33}$ This study nearly correlates with our study.

HbA1c was more than 8 in $65.3 \%$ patients which show poor diabetic control. A significant positive association of the glycated hemoglobin level and diabetic neuropathy has been found, which indicates the role of poor glycemic control in the development of diabetic neuropathy. ${ }^{27}$ Poor glycemic control in patients with diabetic foot ulcers has been found in other studies. ${ }^{15,26,27,29}$

Hypertension, ischemic heart disease and dyslipedimia were found in $46.6 \%, 20 \%$ and $50 \%$ respectively. These all are significant independent risk factors for the development of neuropathy, PVD and diabetic foot ulcers as shown in other studies. ${ }^{26,32}$

Nephropathy and retinopathy was observed in $13.3 \%$ and $12 \%$ respectively. Nephropathy can lead to end stage renal disease while retinopathy can cause diminished visual acuity which is a major cause of foot injury as the patient cannot see the objects.

Structural foot deformity is another risk factor for the development of diabetic foot ulcer. Peripheral vascular disease and neuropathy augment the risk of foot ulcer many fold in patients with foot deformity. Foot deformities are more common in diabetic patients due to atrophy of the intrinsic musculature responsible for stabilizing the toes. ${ }^{32,35,36}$ It was present in $42 \%$ of our patients.

Accidental/ foot wear trauma was noted in $44 \%$ of patients. Ill-fitting shoes were the commonest cause of foot wear trauma in our study.

Foot infection was present in $74 \%$ of patients. Although it is not directly related to development of foot ulcers but can lead to osteomylitis, chronic ulceration and foot amputation. ${ }^{26,37}$

\section{CONCLUSION}

Obesity, poor glycemic control, peripheral neuropathy, peripheral vascular disease, dyslipidemia and accidental or footwear trauma are the major contributory risk factors leading to development of diabetic foot ulcer. Therefore every physician sitting in primary health facility should have ample knowledge of diabetes mellitus, its early diagnosis and proper management.

\section{Copyright $\subset 09$ Apr, 2016.}

\section{REFRENCES}

1. Masharani U. Diabetes Mellitus and Hypoglycemia. Current Medical Diagnosis and Treatment, 2015. 54 Ed. P. 1184.

2. Global status report on no communicable diseases 2014. Geneva, World Health Organization, 2012.

3. World Health Organization. Global Health Estimates: Deaths by Cause, Age, Sex and Country, 2000-2012. Geneva, WHO, 2014.

4. American Diabetes Association. Diabetes Statistics. Data from the 2011 National Diabetes Fact Sheet. http://www.diabetes.org.

5. Driver VR, Fabbi M, Lavery LA, Gibbons G. The costs of diabetic foot: The economic cases for the limb salvage team. J Vasc Surg. 2010; 52(3):17S-22S.

6. The Nation. WHO ranks Pakistan 7th on diabetes 
prevalence list 2008. Available from: http://www.nation. com.pk/.

7. Malik MA. Proceedings of RCP London Regional Conference at FJMC Lahore. Pulse International 2006; $7(7): p 6$.

8. International Diabetic Federation Diabetes 2006. Available from: http:// www.idf.org.

9. Khuwaja AK, Fatmi Z, Soomro WB, Khuwaja NK. Risk factors for cardiovascular disease in school children: a pilot study. J Pak Med Assoc. 2003; 53: 396-400.

10. Levy JM, Valabhij J. The Diabetic Foot. Surgery International 2005; 68: 20-3.

11. Sharma VKI, Khadka PB, Joshi A, Sharma R. Common pathogens in diabetic foot infection in Bir hospital. Kathmandu Univ Med J. 2006; 4(3): 295-301.

12. Reiber GE, Boyko EJ, Smith DG: Lower extremity foot ulcers and amputations in diabetes. In Diabetes in America. 2nd ed. $\mathrm{H}$ a rris MI, Cowie CC, Stern MP, Boyko EJ, Reiber GE, Bennett PH, Eds. Washington , DC, U.S. Govt. 1995, p. 409-428.

13. Pecoraro R, Reiber G, Burgess E. Pathways to diabetic limb amputation: a basis for prevention. Diabetes Care 1990; 13:513-21.

14. Boulton AJ, Armstrong DG, Albert SF, Frykberg RG, Hellman R, et al. Comperhensive Foot Examination and Risk Assessment. Diabetes Care 2008; 31: 167985.

15. Ali S, Basit A, Sheikh T, Mumtaz S, Hydrie M. Diabetic foot ulcer-a prospective study. J Pak Med Assoc. 2001; 51(2): 78-81.

16. Selden C, Zorn M, Ratzan SC, Parker RM. Health literacy. Bethesda (MD): National Library of Medicine; 2000 Feb.

17. Davis WA, Norman PE, Bruce DG, Davis TM. Predictors, consequences and costs of diabetes-related lower extremity amputation complicating type 2 diabetes: The Fremantle diabetes Study. Diabetologia 2006; 49(11): 2634-41.

18. Singh N, Armtsrong DG, Lipsky BA. Preventing diabetic foot ulcers in patients with diabetes. JAMA 2005; 293(2): 217-28.

19. Vilei kyte L. Stress on wound healing. Clinics in dermatology 2007; 25: 49-55.

20. M. shenaq, S.M. Klebue, MJA Bargo: How to help diabetic patients avoid amputations. Prevention andmanagement of foot ulcers. Post-Graduate Medicine. 1994; 96: 191-2.

21. Margolis DJ, Kantor J, Jesse A, Berlin SDD: Healing of diabetic neuropathic foot ulcer receiving standard treatment- A meta analysis, Diabetes Care, 1992; 22: 692-5.

22. Brismar G, Fagrell B. Skin Capillary Circulation is more impaired in neuropathy in the diabetic foot. New concepts in the etiology and treatment. In: Levin Mc O'Neal LW (edi). The diabetic foot, St louis: CV Mosby 1998; P: 76-263.

23. Yonem A, Cakir B, Guler S, Azal OO, Corakei A. Effects of granulocyte-colony Stimulating factor in the treatment of diabetic foot infection. Diabetes Obes Metab 2001; 3(5): 332-7.

24. Boulton AJM. The diabetic foot. Diabet. Med. 2006; 34 : 87-90.

25. Muqim R, Griffin S, Ahmed M. Evaluation and management of diabetic foot according to Wagner's Classification. A study of 100 cases. J Ayub Med Coll 2003; 15(3): 39-42.

26. Khan H, Khan Z, Khan I, Din J, Rehman S, et al. Factors contributing to the development of diabetic foot ulcers and role of health literacy. A study of 100 patients. Rawal Med J. 2011; 36(1): 34-7.

27. Mahroos FA, Roomi KA. Diabetic neuropathy, foot ulceration, peripheral vascular disease and potential risk factors among patients with diabetes in Bahrain: A nationwide primary care diabetes clinic-based study. Annals of Saudi Medicine, 2007; 27(1): 25-31.

28. Nasreen S, Ahmed I, Jahangir MU. Cutaneous manifestations of diabetic foot. J Pak Assoc Derma 2009; 19: 12-6.

29. Boyko EJ, Forsberg RC, Ahroni JH, Davignon DR, Stensel $\mathrm{V}$, et al. A prospective study of risk factors for diabetic foot ulcer. The Seattle Diabetic Foot Study. Diabetic care, 1999; 22: 1036-42.

30. Rehman F, Nadir S, Noor S. Diabetic foot. J Postgrad Med Inst, 2004; 18(3): 463-9.

31. Akbar N, Bilai N. The sweet foot: Relation of glycemic control with diabetic foot lesions. Int J Pathol, 2004; 2(2): 91-4.

32. Pham H, Armstrong DG, Harvey C, Harkless LB, Giurini $\mathrm{JM}$, et al. Screening techniques to identify people at risk for diabetic foot ulceration. A prospective multi centre trial. Diabetes Care 2000 May; 23 (5): 606-11. 
33. Ali SM, Basit A, Fawwad A, Ahmedani MY, Miyan Z, et al. Presentation and outcome of diabetic foot at a tertiary care unit. Pak J Med Sci 2008; 24(5): 651-56.

34. Maskari FA, Sadiq ME. Prevalance of risk factors for diabetic foot complications. BMC Family Practice 2007; 8: 59.

35. Jeffcoate WJ, Harding KG. Lancet 2003; 361:1545-51.
36. Armstrong DG, Lavery LA. Diabetic Foot Ulcers: Prevention, Diagnosis and Classification. Am Fam Physician. 1998; 57(6): 1325-32.

37. Khoharo HK, Ansari S, Qureshi F. Diabetic foot ulcers; common isolated pathogens and in vitro antimicrobial activity. Professional Med J 2009; 16(1); 53-60.

\section{PREVIOUS RELATED STUDY}

Altaf Hussain Rathore. DIABETIC FOOT. (Editorial) Prof Med Jour 16(4) 472-474 Oct, Nov, Dec 2009.

Haji Khan Khoharo, Shuaib Ansari, Fatima Qureshi. DIABETIC FOOT ULCERS (Original) Prof Med Jour 16(1) 49-53 an, Feb, Mar 2009.

Johar Ali, Ali Akbar, Waqas Anwar. DIABETIC FOOT ULCER GRADES; CORRELATION WITH ANKLE BRACHIAL PRESSURE INDEX (Original) Prof Med Jour 15(1) 133 - 136 Jan, Feb, Mar, 2008.

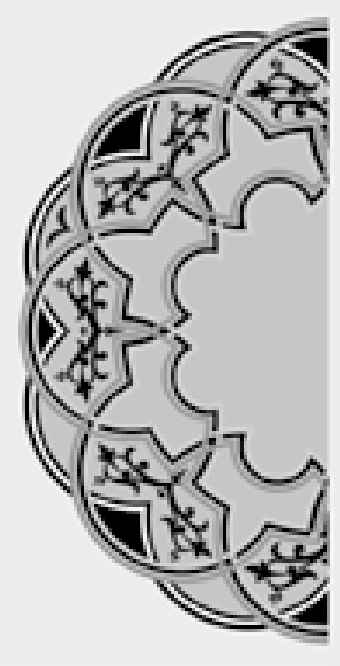

\section{"Every saint has a past. Every sinner has a future."}

\section{AUTHORSHIP AND CONTRIBUTION DECLARATION}

\begin{tabular}{|c|c|c|c|}
\hline Sr. \# & Author-s Full Name & Contribution to the paper & Author $=\mathbf{s}$ Signature \\
\hline 1 & Dr. Abdul Waheed Jan & Conception \& Design & \\
\hline 2 & Dr. Hanifullah Khan & $\begin{array}{l}\text { Writing of manuscript } \\
\text { Statistical analysis \& }\end{array}$ & \\
\hline & (20) & $\begin{array}{l}\text { guidance in writing the } \\
\text { manuscript }\end{array}$ & \\
\hline 3 & Dr. Ishtiaq Ahmad & $\begin{array}{l}\text { Data collection \& } \\
\text { compiling results }\end{array}$ & \\
\hline 4 & Dr. Matiullah Khan & $\begin{array}{l}\text { Writing the article, Critical } \\
\text { revision of the article }\end{array}$ & \\
\hline
\end{tabular}

